IZA DP No. 6411

Information and Competition Entry

Mara Ewers

March 2012 


\title{
Information and Competition Entry
}

\author{
Mara Ewers \\ University of Bonn \\ and IZA

\section{Discussion Paper No. 6411 \\ March 2012} \\ IZA \\ P.O. Box 7240 \\ 53072 Bonn \\ Germany \\ Phone: +49-228-3894-0 \\ Fax: +49-228-3894-180 \\ E-mail: iza@iza.org
}

Any opinions expressed here are those of the author(s) and not those of IZA. Research published in this series may include views on policy, but the institute itself takes no institutional policy positions.

The Institute for the Study of Labor (IZA) in Bonn is a local and virtual international research center and a place of communication between science, politics and business. IZA is an independent nonprofit organization supported by Deutsche Post Foundation. The center is associated with the University of Bonn and offers a stimulating research environment through its international network, workshops and conferences, data service, project support, research visits and doctoral program. IZA engages in (i) original and internationally competitive research in all fields of labor economics, (ii) development of policy concepts, and (iii) dissemination of research results and concepts to the interested public.

IZA Discussion Papers often represent preliminary work and are circulated to encourage discussion. Citation of such a paper should account for its provisional character. A revised version may be available directly from the author. 


\section{ABSTRACT}

\section{Information and Competition Entry ${ }^{*}$}

This paper studies the influence of information on entry choices in a competition with a controlled laboratory experiment. We investigate whether information provision attracts mainly high productivity individuals and reduces competition failure, where competition failure occurs when a subject loses the competition because the opponent holds a higher productivity. Information on the opponent is a promising nudge to raise individuals' awareness towards the complexity of the decision problem and to update beliefs about success. In the experiment, subjects face the choice between a competition game and a safe outside option. We analyze subjects' entry behavior with a benchmark treatment without information and three treatments, where we exogenously manipulate the information on the opponents. Our results are, (1) information on the productivity distribution of all potential opponents reduces competition failures by more than $50 \%$, (2) information on the distribution is sufficient, i.e. precise information on the matched opponent's type does not further diminish failure rates.

JEL Classification: C91, D03, D61, D81, D82, M13, M51

Keywords: competition, experiment, information, overconfidence, self-assessment, self-selection, tournament

Corresponding author:

Mara Ewers

University of Bonn

Kaiserstr. 1

53113 Bonn

Germany

E-mail: mewers@uni-bonn.de

\footnotetext{
*I thank Steffen Altmann, Armin Falk, Sebastian Goerg, Andreas Grunewald, Paul J. Healy, Matthias Kräkel, Luis Santos-Pinto, Daniel Schunk, Matthias Wibral, Florian Zimmermann, participants of the Bonn "retreat", the Economic Science Association World Meeting in Copenhagen (2010), and the Bonn BGSE Micro workshop (2011) for fruitful discussions and comments. Financial support from the Bonn Graduate School of Economics (BGSE) is gratefully acknowledged.
} 


\section{Introduction}

Competition is a major force of economic behavior and interactions. Examples of competition are business formation, job promotion, occupational choice, or sports tournaments. The decision to enter a competition clearly depends on individuals' private self-assessment about productivity. However, absolute and relative self-assessments about productivity are often inaccurate (e.g. Weinstein (1980), Taylor and Brown (1988)). As a consequence of overconfident self-assessments and neglecting the productivity of the opponents, Camerer and Lovallo (1999) find excessive market entry in a laboratory experiment. Too many subjects entered the market and therefore the market share is lower than an outside option. Similarly, competition failure often yields less monetary utility than an outside option, where competition failure occurs if an individual loses the competition, because the opponent holds a higher productivity. For example, new businesses frequently fail after inception as a result of overconfidence and entrepreneurs earn less money than in a paid job according to their productivity (e.g. Koellinger, Minniti, and Schade (2007)).

The goal of our study is to explore whether information influences entry decisions in a competition game. We ask whether information on the opponents reduces competition failure by preventing entry of overconfident individuals and by attracting mainly high productivity types. Competition failure is an especially interesting criteria, because it informs us about the frequency of individuals that waste money due to losing the competition instead of choosing a higher outside option. Evidently, information is beneficial in various contexts for the decision making process. In the competition game, information can nudge individuals to update their productivity beliefs and think more carefully about the chances of success. In consequence, we expect fewer competition failures. However, the updating process might not be correctly applied and it is possible that information even fosters the overconfidence bias. We discuss the effects of absolute and relative self-assessment biases on entry choices in the competition game and when information might be beneficial. The latter results as an outcome of the magnitude of self-assessment biases and the updating process, which we therefore explore empirically with a lab experiment.

For the ideal empirical analysis of the effect of information on entry choices, we need to have control over the information available to each individual. In addition, we need clean measures of individuals' productivity and self-assessments about productivity. Therefore, we make use of the 
advantages of a controlled laboratory experiment instead of a field experiment. In the competition game success depends on the productivity of an ex ante performed quiz task. We elicit absolute and relative self-assessments about subjects' quiz performance. Subjects are randomly matched in groups of two and decide about entering the competition or opting for an outside payment. A subject wins the competition, if the matched opponent did not enter, or if she has a higher productivity than the opponent. We set up a benchmark treatment, No Info, in which subjects received no additional information and three information treatments with a between-subject design. In treatment Distribution, the productivity distribution of all subjects in the session is revealed, before subjects made their decision to enter. In treatment True, we reveal more precise data on the matched opponent, that is the matched opponent's true productivity. To study whether there is a discouraging or encouraging impact of the opponent's over- or underconfidence, we study in treatment True \& Belief, the entry choice by disclosing information on the matched opponent's productivity and her absolute self-assessment. This variation of aggregated and precise information allows us to exactly measure the frequency change of entry choices and competition failure rates for each treatment.

Competition entry in the information treatments is significantly lower compared to the benchmark treatment. We find evidence for competition failure especially in the benchmark treatment, No Info, which is mainly driven by overplacement, i.e. neglecting the productivity of the opponents (similar to Camerer and Lovallo (1999)), instead of overestimation, gender or willingness to take risks. Analyzing the data of the information treatments reveals sizable and significant improvements by information. The two major findings are, 1 . competition failures decrease by $57 \%$, when providing information on the productivity distribution, and 2. more precise information does not further improve entry choices. This implies, that simple and aggregated information on the productivity distribution is sufficient to decrease competition failure rates by a striking value. Furthermore, our data show that the decision to enter depends strongly on productivity in the information treatments, but not in the benchmark treatment. This complements the usefulness of information disclosure to attract high productivity individuals for the competition. Disclosing the opponent's productivity has a high and significant influence on entry. In addition, the knowledge of an overconfident opponent discourages entry, but not in a significant way. Note that we do not analyze a strategic choice of self-assessments on the opponent's entry choice. Reuben, Rey-Biel, Sapienza, and Zingales (2010) 
show that exaggerating one's self-assessment strategically in a team environment, helps to become the leader of a team. And Charness, Rustichini, and van de Ven (2011) find a similar result for a competition environment where the disclosure of the opponent's high self-assessment discourages competition entry. The main difference to the present paper is that both papers do not disclose the true productivity at the same time as they disclose the self-assessment. Furthermore, we confirm the finding of Niederle and Vesterlund (2007), who point out that due to a gender difference in overconfidence, women shy away from competitive environments more frequently compared to men, in the benchmark treatment and treatment Distribution.

A large literature in psychology and experimental economics emphasizes the finding of selfassessment biases.1] The consequences have been studied in various economic environments like business contexts. For example, Cooper, Woo, and Dunkelberg (1988) conclude that entrepreneurs overestimate their chances of success with their new business, which in consequence leads to competition failure. Also, Dunning, Meyerowitz, and Holzberg (1989) and Baldwin (1995) report business failures shortly after market entry. For a similar survey study and a recent overview see Koellinger, Minniti, and Schade (2007). In addition, overconfidence has been highlighted as a major force in costly delays in labor negotiations, excessive litigation, excessive stock trading and subsequent market volatility, (see, e.g. Neale and Bazerman (1985), Odean (1998), Daniel, Hirshleifer, and Subrahmanyam (2001), Malmendier and Tate (2008)). Our findings contribute to this literature by showing how consequences of self-assessment biases can be mitigated in a competition environment. In addition, our study contributes to the literature on sorting behavior in competitive environments. A competition is usually set up to attract high productivity types. Dohmen and Falk (2011) conclude that in addition, relative self-assessments, gender, and willingness to take risks are vital personal attitudes that effect competition entry choices when studying decision making of students in a laboratory experiment and also of a representative sample of the German population. Experimental studies on entry decisions by Camerer and Lovallo (1999), Niederle and Vesterlund (2007), Bartling, Fehr, Marechal, and Schunk (2009) also show that subjects with high relative self-assessments self-select into the competition more frequently.

\footnotetext{
${ }^{1}$ Several explanations, for why self-assessment biases are present in many contexts and still persist have been proposed, for instance self-image concerns (Bénabou and Tirole (2002), Köszegi (2006)), asymmetrical processing of positive and negative information (e.g. Brunnermeier and Parker (2005), Möbius, Niederle, Niehaus, and Rosenblat (2011)), or social image concerns (e.g. Burks, Carpenter, Goette, and Rustichini (2010), Ewers and Zimmermann (2011)).
} 
In the last years, a growing literature on libertarian paternalism by psychologists and economists aims at encouraging and supporting individuals in economic and non-economic decision finding (e.g. Thaler and Sunstein 2003, 2008) ). Examples are the analysis of optimal default options (e.g. Choi, Laibson, Madrian, and Metrick (2003)) or school interventions. Our study contributes to this literature by showing that providing simple and inexpensive information helps our subjects to make better decisions in the competition game. Our controlled laboratory findings might have similar effects in real life situations of competitive environments. An established application where information of past performances is used to decrease allocation and application costs, is the university place allocation system $Z V S$ in Germany. Here, prospective students learn the distribution of school grades of former accepted students for the respective field and university of the last year before applying. Other possible implementations in practice might be interventions at employment agencies or firms. For instance, public and private employment agencies could emphasize the importance of the opponents productivity in a competition by providing information about market characteristics, where startup businesses want to engage in. Firms often collect data about workers' productivity, effort, cognitive and non-cognitive skills. Before announcing (internal) job-promotions, firms could disclose anonymously the productivity outcomes of former workers to reduce irrelevant applications. Banks or venture capital companies, that finance credits for startup businesses could disclose probabilities of success for the market segment.

The remainder of the paper is organized as follows. Section 2 outlines the theoretical framework of the competition game. In Section 3, we present the experimental design and Section 4 provides the results. Finally, Section 5 concludes.

\section{The Competition Game}

Before the competition entry game starts, $N$ players independently engage in a task in which their performance can be quantified precisely. Let $a_{i}$ and $a_{j}$ represent player $i$ and $j$ 's performance drawn from the discrete productivity distribution $F(a)$. Further, let $X$ be the random variable representing players' productivity ranking from 1 to $N$ in the population with generic realization $x_{i}$ and $x_{j}$, respectively. The competition game consists of two players, randomly drawn from the population of $N$ players that decide about the entry decision $e \in\{0,1\}$. For the following analysis, 
we assume that players are risk neutral. If a player does not enter the competition, she receives an outside option $W_{o}$. If only one player enters the competition, she wins the competition automatically and receives the winner prize $W_{h}$. If both players enter the competition, the player with the highest productivity $a$ wins the competition and the loser receives the loser prize $W_{l} 2^{2}$ The loser prize is smaller than the outside option, otherwise all players enter the competition. If players with the same productivity enter, a player wins either the winner or loser prize with probability 0.5. Thus, player $i$ 's productivity of the previous task is relevant for the probability of winning the competition. The

only action of the players is to decide about the entry decision $e$. The utility of an unbiased and risk neutral player $i$ is then given by

$$
u_{i}(a)=\left\{\begin{array}{cc}
\operatorname{Pr}\left(e_{j}=1\right)\left[F\left(a_{i}>a_{j} \mid e_{j}=1\right) W_{h}+F\left(a_{i}=a_{j} \mid e_{j}=1\right)\left(\frac{W_{h}+W_{l}}{2}\right)+\right. & \\
\left.\left(1-F\left(a_{i}>a_{j} \mid e_{j}=1\right)\right) W_{l}\right]+\left(1-\operatorname{Pr}\left(e_{j}=1\right)\right) W_{h} & \text { if } \quad e_{i}=1 \\
W_{o} & \text { if } \quad e_{i}=0
\end{array},\right.
$$

where $\operatorname{Pr}\left(e_{j}=1\right)$ is the probability that a random opponent $j$ enters the competition.

By inspection of formula (1), we find that player $i$ should enter the competition, if her winning probability $F\left(a_{i}>a_{j} \mid e_{j}=1\right)$ is high or if the probability that the opponent enters the competition is low:

$$
F\left(a_{i}>a_{j} \mid e_{j}=1\right)>1-\frac{\operatorname{Pr}\left(e_{j}=1\right) F\left(a_{i}=a_{j} \mid e_{j}=1\right)\left(\frac{W_{h}+W_{l}}{2}\right)+\left(W_{h}-W_{o}\right)}{\operatorname{Pr}\left(e_{j}=1\right)\left(W_{h}-W_{l}\right)}
$$

\subsection{Overconfidence}

Let us now consider the effect of systematic self-assessment biases. Assume that players are unaware of their true performance $a$, but have a point belief which we denote as subjective performance $a_{i}+\triangle_{i}$ and $a_{j}+\triangle_{j} !^{3}$ A player's subjective perception of her position in the ranking is denoted by $x_{i}-\Lambda_{i}$. Then, we can define the following two concepts of systematic self-assessment biases (similar to Healy and Moore (2008a) ):

Definition 1: Player $i$ exhibits overestimation if $\triangle_{i}>0$ and underestimation if $\triangle_{i}<0$. If

\footnotetext{
${ }^{2}$ The fix costs of competition entry are the same for all players and included in the prizes.

${ }^{3}$ The assumption of a point belief is a simplification. A distributed belief might capture a more realistic view, but does not supply any additional insights on our study.
} 
either is true, $i$ exhibits misestimation.

Definition 2: Agent $i$ exhibits overplacement if $\Lambda_{i}>0$ and underplacement if $\Lambda_{i}<0$. If either is true, $i$ exhibits misplacement.

If players hold a systematic bias about their productivity belief, their subjective utility of the competition game does not coincide with formula (1). A player that holds the absolute selfassessment $a_{i}+\triangle_{i}$ can overestimate or underestimate her subjective winning probability $P\left(a_{i}+\triangle_{i}>\right.$ $\left.a_{j} \mid e_{j}=1\right)$ depending on whether $\triangle_{i}$ is positive or negative. Overconfidence about productivity according to an overestimation bias, results in a higher subjective winning probability compared to the true winning probability $F\left(a_{i}>a_{j} \mid e_{j}=1\right)$. Similarly, a player with a misplacement bias holds the relative self-assessment $x_{i}-\Lambda_{i}$ about her ranking of all players. Her subjective winning probability in formula (2) is then $P\left(x_{i}-\Lambda_{i}<x_{j} \mid e_{j}=1\right)$, because the high productivity types have a small placement number $x$. Thus, we find that overconfidence finds different expressions in the subjective winning probability and yields to a higher subjective winning probability compared to the true winning probability, which leads to our hypothesis on entry behavior that we explore with the laboratory experiment:

Hypothesis on Entry behavior: If a player is unbiased $(\triangle=0 / \Lambda=0)$, then she enters the market less often than a player who overestimates or overplaces her productivity $(\triangle>0 / \Lambda>0)$ holding everything else constant.

\subsection{Efficiency of information}

Information is obviously a strong tool to improve decision making in various contexts. Receiving information on the opponent reduces uncertainty in the game and attracts the attention to the fact that the decision problem depends highy on the opponents productivity. In addition, individuals can update their self-assessment, which might reduce the self-assessment bias. However, in our two player game both players receive information at the same time. Therfore, additional information might not necessarily be beneficial. The way how individuals update their self-assessment is also 
crucial. Whether an overconfident individual updates her belief downwards or rather fosters the overconfident belief has an influence on the entry choice. Furthermore, the investigation of selfassessment biases does always entail a discussion of higher order beliefs. The belief about what others believe is of interest in this two player game, too. If a player assumes that other players are underconfident, she will enter the competition too often.

We start the discussion with the effect of information on the productivity distribution of all $N$ players, i.e. $F(a)$. If players hold perfect beliefs about their productivity $a$ and the distribution $F(a)$, as assumed in formula (1), we expect no difference in entry decisions by providing information on $F(a)$. However, the literature on self-assessment biases emphasizes that many individuals hold too optimistic beliefs about their absolute and relative productivity. On the one hand, knowing the distribution about productivity reduces uncertainty and we expect less wrong entry decisions. On the other hand, it is very important how individuals actually use their new information to update beliefs. For example, a player with a correct absolute self-assessment and an overconfident relative self-assessment should optimally update the relative self-assessment by updating it downwards. An overconfident player might instead prefer to update her actually correct absolute self-assessment upwards.

We analyze also the effect of information on the opponent's productivity type. In this scenario, both players know exactly the productivity of the matched opponent. For the analysis with unbiased and rational players, we should observe no competition failures since uncertainty is resolved. The player with the higher productivity always enters and the other chooses the outside option. When type uncertainty plays a role, the only relevant belief for the entry choice is then the belief about the absolute self-assessment, if we do not consider higher order beliefs. We analyze one further information treatment to study the effect of the opponent's self-assessment on a player's entry choice.

In addition, we study how the entry choice is influenced by over- and underconfidence of the opponent by disclosing the true productivity of the opponent, and also, we disclose the productivity self-assessment of the opponent. The information of an overconfident opponent indicates that the opponent enters very certainly and might discourage a player to enter. Or an underconfident opponent encourages the entry decision although the opponent has a higher productivity.

The purpose of this paper is to detect what information is a simple and inexpensive way to 
decrease competition failure. Obviously, we need to make several assumptions on absolute and relative self-assessment biases, belief updating and higher order beliefs, to claim that information about the productivity distribution is beneficial. An analysis of these channels and its interaction is an interesting task to deepen the understanding of individuals' processing with uncertainty, however, it is not the focus of our paper. We will analyze the effect of the information on entry choices empirically within the experiment.

\section{Experimental Design}

In the ideal experimental set up for a clean analysis of competition entry decisions, we need to know subject's beliefs about their own and relative productivity, their true productivity, and further individual characteristics like willingness to take risks and gender. We conduct our experiment in the laboratory instead of conducting a field experiment, because we gain important control about the information each subject has and we can precisely manipulate and vary the information provision. Confounding factors that might influence subjects beliefs are ruled out and additional information about further key variables is available, e.g. risk attitudes and entry costs.

We present now the four main parts of our experiment. In the first part, we pin down subjects productivity for the competition. In part two, subjects assess their absolute and relative beliefs about productivity. In part three, subjects play the competition entry game and receive information or not about the opponent previous to their entry choice. In part four we analyze subjects' willingness to take risks. Finally, the experiment ends with a questionnaire after the risk task.

In the first part, subjects' productivity is determined by a multiple-choice quiz of 20 questions and no time limit. The quiz contained questions concerning history, arts, economics, and orthography. Subjects received 20 points for a correct quiz answer. All monetary quantities of the experiment are denominated in points; 100 points are equal to one euro. Subjects did not receive feedback on the number of correct quiz answers or the amount of earned money. Thereby, subjects could not learn their true quiz productivity, where quiz productivity is defined as the sum of correct quiz answers (denoted as $a$ in section 2). We employed five incentivized self-assessment questions to elicit subjects' absolute and relative self-assessments on quiz productivity. Not all five, but only one measure was paid to impede any hedging motives. We studied different questions to receive overes- 
timation and overplacement measures and to perform consistency and robustness checks. 4 The first two questions were used to analyze overestimation: (i) How many quiz questions have you solved correctly? (ii) For the second overestimation measure, subjects had to distribute 100 points into 21 categories. Every category was associated with the number of correct quiz answers and all points had to be distributed 5 Our three questions on overplacement are: (iii) Is your quiz-performance one of the best half or worst half of quiz-performances of all participants in the room?, (iv) How many of the other participants in the room solved more quiz questions correct than you?, (v) How many of the other participants in the room have less correct answers than you? A subject's payoff for (iii) was 100 points for a correct assessment. Subject's payoff for (i), (ii), (iv) and (v) was 200 points for a correct assessment and 50 points for guessing one category next to the correct answer. We define overconfidence and underconfidence by calculating the difference between the actual quiz performance and the five statements (see Table 6 in the Appendix A for more details).

After subjects' quiz assessment, we conducted the competition game in the third part of the experiment. We employed a between subject design for the study of four treatments including a benchmark treatment and three information treatments. Subjects were randomly matched in pairs of two and decided to enter the competition or not. Before they made their decision, we provided information according to the treatment they participated in. In the benchmark treatment, No Info, they received no additional information on the opponent's type. In the Distribution treatment, we provided the productivity distribution of all subjects in the room by showing a table with the amount of subjects that had $0,1,2, \ldots, 20$ questions correct on the screen. In treatment True, our subjects knew the number of correctly solved questions of their matched opponent. In treatment True $\mathscr{6}$ Belief, each subject received information on the matched opponent's productivity and productivity belief from the self-assessment question (i) (see also Table 2 for an overview of all treatments). This was not known to subjects when they answered the self-assessment questions 6 We can then study exactly what kind of information reduces or increases competition entry and competition failure. The rules of the game correspond to the ones in section 2. A subject won the competition if the

\footnotetext{
${ }^{4}$ The studies by Healy and Moore (2008a) and Healy and Moore (2008b) point out that the distinction of overconfidence in overestimation and overplacement is crucial for the decision making process and much of the previous literature confuses these two concepts.

${ }^{5}$ For example, a subject that is sure to have answered more than one question correct should place zero points into category " 0 " and " 1 ".

${ }^{6}$ For strategic choices of reports of self assessments see for example Ewers and Zimmermann (2011) or Charness, Rustichini, and van de Ven (2011).
} 
Table 1: Information treatments

\begin{tabular}{ll}
\hline \hline Treatment & Information \\
\hline No Info & No information about the opponent's type \\
Distribution & $\begin{array}{l}\text { Information about the productivity distribution of subjects in the room } \\
(F(a))\end{array}$ \\
True & $\begin{array}{l}\text { Information about the opponent } j \text { 's productivity } a_{j} \\
\text { True } 6 \text { Belief }\end{array}$ \\
& $\begin{array}{l}\text { Information about the opponent } j \text { 's productivity } a_{j} \text { and } j \text { 's } \\
\text { productivity belief } a_{j}+\triangle_{j}\end{array}$ \\
\hline
\end{tabular}

subject entered and the matched subject did not enter or had a lower quiz productivity. If both entered with the same productivity, a subject won with $50 \%$. The prizes for winning and losing were: $W_{h}=400$ and $W_{l}=100$. Opting for the outside option gave $W_{o}=200$. To secure the understanding of the game, we asked several control questions before the game started.

The experiment ended with a task to elicit risk attitudes. Subjects made 30 decisions between a lottery and a secure payoff. The lottery was always the same: It provides a $50 \%$ chance to win 400 points and a $50 \%$ chance to win 100 points. The secure payoff increased from 0 to 400 points. A subject's switching point was used as an indicator for her willingness to take risks.

All sessions of the experiment were conducted at the BonnEconLab at the University of Bonn, subjects were recruited via ORSEE (Greiner (2004)) and we used the software z-Tree by Fischbacher (2007). We conducted eight sessions with 190 subjects from various fields of study and tried to have an equal amount of women and men in every session to analyze a gender effect. Subjects answered all questions and tasks at the computer. At the beginning of the experiment, all subjects knew that the experiment consists of four parts and that they receive the instructions of each of the four parts individually and immediately before the task started.7

\footnotetext{
${ }^{7}$ The instructions of the experiment are available from the author upon request.
} 


\section{Experimental Results}

We first present results on the entry frequency across treatments and the effect of information on competition failure. All tests we use are two-sided. In 4.2 we present the determinants of entry on productivity and personal attitudes and in 4.3, we discuss how overconfidence is distributed and correlated to personal attitudes.

\subsection{Entry frequency and information efficiency}

Result 1 The frequency of entry choices decreases significantly with information compared to the benchmark treatment.

Figure 1: Percentage of competition entry by treatments

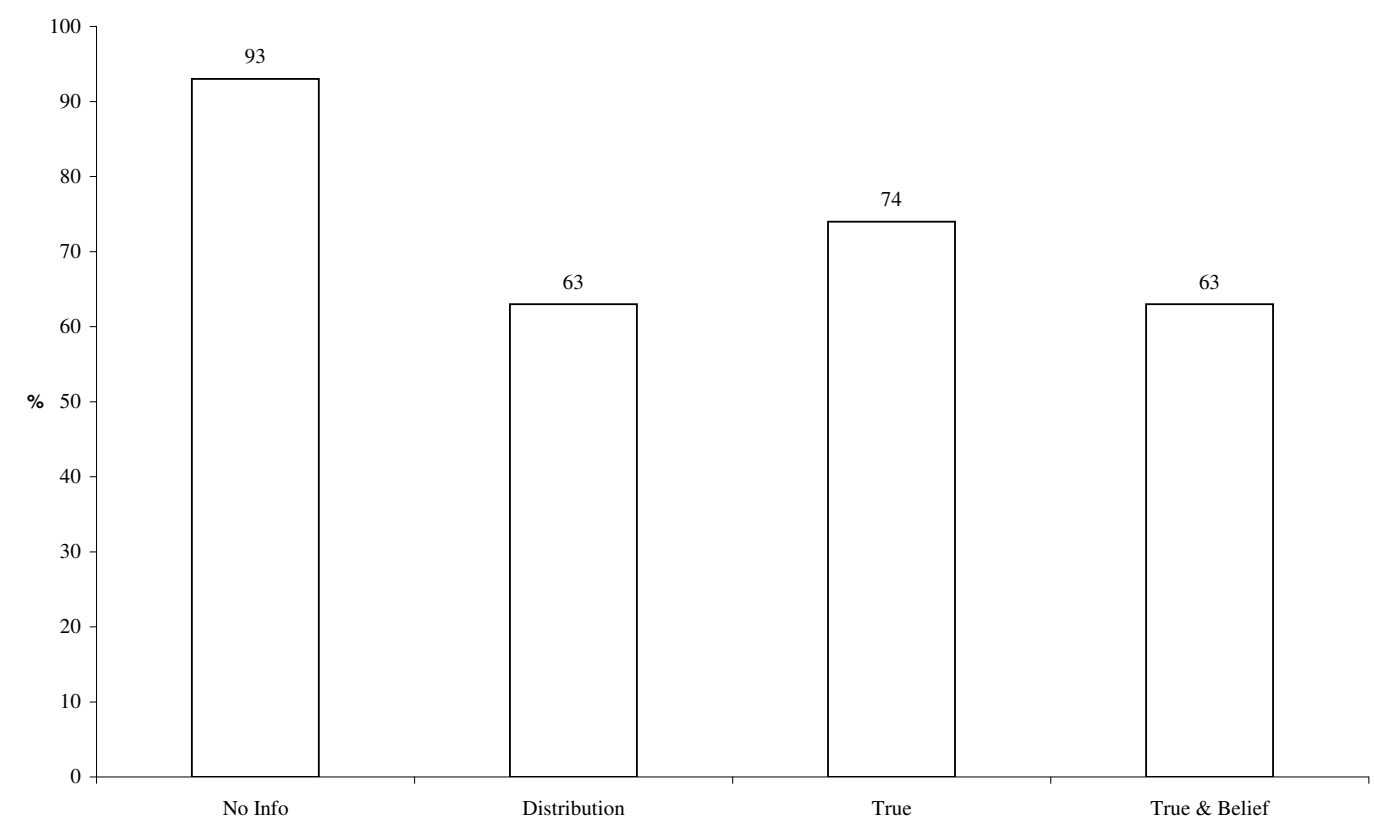

In the benchmark treatment, No Info, a striking number of $93 \%$ of our subjects chose to enter the competition, in treatment Distribution, only $63 \%$ entered, in treatment True $74 \%$ and $63 \%$ 
in treatment True 8 Belief, respectively (see Figure 1). The large amount of entry decisions in the benchmark treatment shows that it is rather a minor problem that underconfident, but high productivity subjects do not enter the competition. The difference of the benchmark treatment compared to the information treatments is sizable. We test whether the large differences in entry frequencies are significant using Fisher-exact tests and find that the entry frequency of each information treatment is significantly different from the benchmark treatment with a $p$-value $=0.001$ for either Distribution or True $\mathscr{E}$ Belief as comparison and $p=0.03$ for treatment True as comparison. The difference is however not significant when testing the frequencies of the information treatments against each other. This implies that the provision of information intensely decreases entry choices, and it is sufficient to provide aggregated data on the distribution of productivity instead of precise information on the opponent. This is an interesting finding for application purposes, because aggregated data might be easier to collect than precise information on the opponent. In the following, we analyze whether the decrease of the entry frequency due to the provision of information, does also decrease competition failure and improve efficient entry choices.

Result 2 The frequency of competition failure is significantly lower in treatment Distribution and True 85 Belief compared to the benchmark treatment without information. The main determinant of competition failure is overplacement instead of overestimation, willingness to take risks or a gender difference.

The goal of this study is to investigate whether information is useful to reduce wrong entry decisions. To answer this question we focus on the criterion competition failure. This criterion is particularly usefull, because it measures how often individuals earn less money than they could actually earn when deciding for the outside option. The data on competition failure reveal a similar picture to the finding of entry frequencies and underline the important result that information does not only decrease entry choices, but more essentially, information prohibits wrong entry choices. We observe $35 \%$ of competition failures in the benchmark treatment, while only $15 \%$ of subjects fail in treatment Distribution, $22 \%$ in treatment True and $15 \%$ in True $\mathscr{G}$ Belief ( see Figure 2). The difference of failure rates in the benchmark compared to Distribution or True 6 Belief is significant in a Fisher-exact test with $p=0.03$ and $p=0.17$ for treatment True vs. No Info . 
Figure 2: Percentage of competition failure by treatments

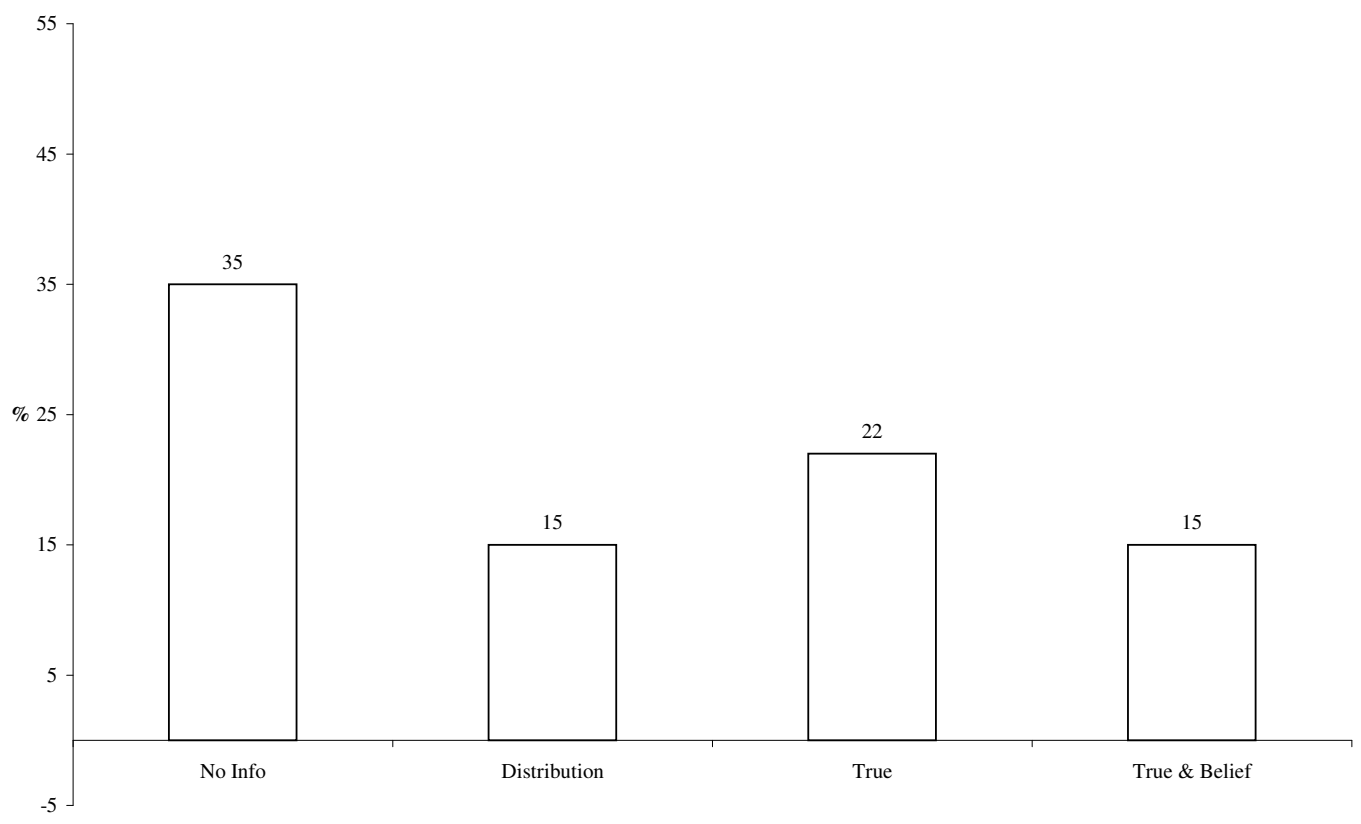

The main driver of competition failure is overplacement, which is in the fashion of a result by Camerer and Lovallo (1999), where neglecting the opponents productivity leads to market failures. Table 3 presents the determinants of competition failure with probit regressions. The dummy variable competition failure takes the value 1 if a subject entered the competition although the subject's productivity is lower than that of the entering matched opponent. We analyze the influence of overestimation and overplacement on competition failure by using subjects reports to question (i) and (iv) ${ }^{8}$ of the self-assessment stage and compare them with the true productivity and productivity ranking $9^{9}$ We also control for risk attitudes and gender. We find a significant influence of overplacement in treatment No Info. Subjects that believe they are better than others experience a competition failure significantly more often. This effect vanishes when providing information and it is only weakly significant in treatment True $\mathscr{G}$ Belief. We do not find that willingness to take

\footnotetext{
"How many quiz questions have you solved correctly?" and "How many of the other participants in the room solved more quiz questions correct than you?"

${ }^{9}$ Using any of the other overconfidence definitions does not change the qualitative results.
} 
risks or gender has explanatory power in determining competition failure. The general self-selection analysis will be discussed in the next section.

Table 2: Determinants of competition failure

\begin{tabular}{|c|c|c|c|c|}
\hline \multicolumn{2}{|c|}{ Dependent variable: Competition failure $=$} & \multicolumn{3}{|c|}{$\begin{array}{c}1 \text { if } e_{i}=e_{j}=1 \text { and } a_{i}<a_{j} \\
0\end{array}$} \\
\hline & No Info & Distribution & True & True $\&$ Belief \\
\hline Overplacement (iv) & $\begin{array}{c}0.15 * * * \\
(0.04)\end{array}$ & $\begin{array}{c}0.10 \\
(0.08)\end{array}$ & $\begin{array}{c}0.08 \\
(0.06)\end{array}$ & $\begin{array}{c}0.18^{*} \\
(0.10)\end{array}$ \\
\hline Overestimation (i) & $\begin{array}{l}-0.09 \\
(0.09)\end{array}$ & $\begin{array}{c}0.10 \\
(0.08)\end{array}$ & $\begin{array}{c}0.05 \\
(0.10)\end{array}$ & $\begin{array}{c}0.12 \\
(0.19)\end{array}$ \\
\hline Willingness to take risks & $\begin{array}{c}0.02 \\
(0.10)\end{array}$ & $\begin{array}{l}-0.05 \\
(0.14)\end{array}$ & $\begin{array}{c}0.08 \\
(0.15)\end{array}$ & $\begin{array}{l}-0.31 \\
(0.27)\end{array}$ \\
\hline Dummy gender & $\begin{array}{c}0.24 \\
(0.46)\end{array}$ & $\begin{array}{c}0.32 \\
(0.53)\end{array}$ & $\begin{array}{l}-0.92^{*} \\
(0.51)\end{array}$ & $\begin{array}{c}1.13 \\
(0.84)\end{array}$ \\
\hline Constant & $\begin{array}{l}-1.11 \\
(2.3)\end{array}$ & $\begin{array}{l}-0.25 \\
(3.26)\end{array}$ & $\begin{array}{l}-2.70 \\
(3.55)\end{array}$ & $\begin{array}{c}4.57 \\
(6.09)\end{array}$ \\
\hline $\mathrm{N}$ & 48 & 48 & 46 & 48 \\
\hline$-\mathrm{LL}$ & 23.17 & 16.25 & 19.51 & 11.62 \\
\hline
\end{tabular}

Notes: Coefficients of Probit estimates. Robust standard errors are in parentheses. Significance at the 1, 5, and 10 percent level is denoted by ${ }^{* * *},{ }^{* *}$, and ${ }^{*}$, respectively. The variable Willingness to take risks indicates subjects' switching point from the lottery choice task of part four of the experiment. A high value indicates higher willingness to take risks. The variable Dummy gender takes the value 1 if male.

\subsection{Self-selection}

In Table 4 we present the determinants of entry decisions separately for each treatment and find similar results to previous findings of the literature on sorting behavior in a competitive environment. For the analysis, we classify a subject as overconfident with the following procedure. First, we generate one measure out of our five overconfidence measures with a principal-component-analysis. All of our five overconfidence measures are highly and positively correlated (see Table 5 in the 
Appendix). We extract a linear combination that explains most of the composition of all five measures. The first component score has an eigenvalue of 2.8 and therefore explains $56 \%$ of the composed analysis. Also, all five variables have a similarly large influence on the first component, such that the first component is an appropriate measure. Then, we define a subject as overconfident if the value of the first score is larger than zero and the subject is underconfident if it is smaller than zero.

In the benchmark treatment, all male subjects enter and therefore only female subjects can be included in the analysis of the No Info treatment. We find that productivity has no significant influence on entry in the benchmark treatment. In all other treatments high productivity types enter significantly more often. This is particularly interesting, because it complements our previous results that information is beneficial and is an additional criterion next to competition failure. Due to the provision of information, the competition game attracts significantly often high productivity subjects. The average productivity of subjects that enter in treatment No Info is 12.95 and is lower compared to treatment Distribution, where the average productivity of entrants is 14.23 . In addition, our data show that the well documented gender difference in competition entry behavior (see e.g. Gneezy, Niederle, and Rustichini (2003), Niederle and Vesterlund (2007), Dohmen and Falk (2011)) is also present in treatment No Info and Distribution, but vanishes in treatments True and True $E_{6}$ Belief. This suggests that women are not per se less competitive and information, that reduces uncertainty about the opponent, decreases womens' reluctance to enter the competition.

In treatment True $\mathscr{E}$ Belief we disclose the opponent's self-assessment bias to study whether it has an encouraging or daunting effect on competition entry. Our data reveal that subjects enter the competition less often when facing a very confident subject, however, the effect is not significant. In our experiment, subjects could not choose their self-assessment strategically. Charness, Rustichini, and van de Ven (2011) analyze the effects of a strategic self-assessment choice on entry behavior of the opponent in a tournament environment. They find that subjects are intimidated by a high selfassessment of the opponent and enter less often. Anyhow, they do not reveal the true productivity of the opponent. Table 4 reports that the true productivity of the opponent has a highly significant and sizable effect on entry choices in both treatments True and True $\&$ Belief. This information is seriously taken into account, such that the probability to enter is less likely if the opponent has a high productivity. 
Table 3: Determinants of competition entry

\begin{tabular}{|c|c|c|c|c|}
\hline \multirow[t]{2}{*}{ Dependent variable: } & \multicolumn{3}{|c|}{ Competition entry $=\left\{\begin{array}{ccc}1 & \text { if } & e_{i}=1 \\
0 & & \text { otherwise }\end{array}\right.$} & \multirow[b]{2}{*}{ True $\&$ Belief } \\
\hline & No Info & Distribution & True & \\
\hline Overconfidence & $\begin{array}{c}0.33 \\
(0.30)\end{array}$ & $\begin{array}{l}0.46^{* *} \\
(0.21)\end{array}$ & $\begin{array}{l}1.46^{*} \\
(0.79)\end{array}$ & $\begin{array}{c}0.21 \\
(0.21)\end{array}$ \\
\hline Productivity & $\begin{array}{c}0.04 \\
(0.26)\end{array}$ & $\begin{array}{l}0.39^{* *} \\
(0.18)\end{array}$ & $\begin{array}{l}1.52^{* *} \\
(0.67)\end{array}$ & $\begin{array}{l}0.24^{*} \\
(0.15)\end{array}$ \\
\hline $\begin{array}{l}\text { Opponent's } \\
\text { productivity }\end{array}$ & & & $\begin{array}{c}-1.18^{* *} \\
(0.47)\end{array}$ & $\begin{array}{c}-0.45^{* * *} \\
(0.18)\end{array}$ \\
\hline $\begin{array}{l}\text { Opponent's } \\
\text { productivity } \\
\text { belief }\end{array}$ & & & & $\begin{array}{l}-0.10 \\
(0.12)\end{array}$ \\
\hline $\begin{array}{l}\text { Willingness to } \\
\text { take risks }\end{array}$ & $\begin{array}{l}0.79^{* *} \\
(0.38)\end{array}$ & $\begin{array}{l}0.30^{* *} \\
(0.13)\end{array}$ & $\begin{array}{c}0.29 \\
(0.27)\end{array}$ & $\begin{array}{l}-0.01 \\
(0.13)\end{array}$ \\
\hline Dummy gender & dropped $^{+}$ & $\begin{array}{l}1.75^{* *} \\
(0.75)\end{array}$ & $\begin{array}{c}0.44 \\
(0.71)\end{array}$ & $\begin{array}{c}0.93 \\
(0.72)\end{array}$ \\
\hline Constant & $\begin{array}{c}-17.52^{*} \\
(9.57)\end{array}$ & $\begin{array}{c}-11.96^{* * *} \\
(4.09)\end{array}$ & $\begin{array}{l}-9.43 \\
(9.40)\end{array}$ & $\begin{array}{c}4.68 \\
(3.88)\end{array}$ \\
\hline $\mathrm{N}$ & 24 & 48 & 46 & 48 \\
\hline -LL & 6.4 & 16 & 7.7 & 18 \\
\hline
\end{tabular}

Notes: Probit estimates. Robust standard errors are in parentheses. Significance at the 1,5 , and 10 percent level is denoted by ${ }^{* * *},{ }^{* *}$, and ${ }^{*}$, respectively. The variable Overconfidence is the first component score of the principal component analysis of our five self-assessment measures. The variable Willingness to take risks indicates subjects' switching point from the lottery choice task of part four of the experiment. A high value indicates higher willingness to take risks. The variable Dummy gender takes the value 1 if male. ${ }^{+}$Gender dummy predicts entry perfectly.

\subsection{The existence and robustness of overconfidence}

$71 \%$ of our subjects think their quiz performance is better than the median performance. We observe the existence of overconfidence and underconfidence (see Figure 3 in the Appendix A for histograms of the distribution of all five measures of overconfidence). However, mean and median 
of the overestimation measures are not significantly different from zero. Only the mean, but not the median of our overplacement measures (iv) and (v) is significantly larger than zero with $p=0.02$ and $p=0.06$ of a t-test. The mean and distribution of productivity does not systematically vary across treatments $(p-$ values $>0.4$ of Wilcoxon-ranksum tests and t-tests). The average quiz productivity is 13.5, the worst productivity was 6 correct answers and the best one was 19 correct answers. This indicates a mediocre task difficulty level. Our finding coincides with the results by Healy and Moore (2008a) who find, that easy tasks produce underestimation, difficult tasks produce overestimation, and mediocre tasks produce on average no estimation bias. We find that all of our five elicited measures of overconfidence are significantly and positively correlated. Table 5 in the Appendix reports a correlation table of all confidence measures and productivity. There exists a significantly negative correlation of productivity and overconfidence for the relative and absolute measures, which is robust when controlling for ceiling effects. Due to the definition of overplacement and overestimation, the best performing subjects can never be overconfident and the worst ones can never be underconfident. The negative correlation of overestimation and overplacement with productivity still persists and is significant $(p-$ values $<0.05$ for Spearman-rank tests) when restricting the sample to productivities lower than $20,19,18,17$ or 16.10 Overconfidence in our setting is linked to an especially optimistic belief about one's productivity type, while psychologists describe optimism as a positive view towards uncertain future events or concentrating on the good sides of life. We employ a 10 item questionnaire on optimism at the end of all main tasks of the experiment to analyze a connection to the economic definition of overconfidence. Indeed, we find that the psychological measure of optimism is positively correlated with overplacement $(p=0.08$ of a Spearman-rank test).

\section{Conclusion}

Well adjusted absolute and relative self-assessments about skill, ability or achievements are important to decide about competition entry. However, individuals frequently misestimate their own skill, ability or achievements. In this paper, we study a competition game where players might have an

\footnotetext{
${ }^{10}$ The low productivity players can always underestimate their productivity. However the worst players can not underplace themselves. Omitting the best and worst subjects, the negative correlation of overplacement and productivity is still significant.
} 
absolute or relative self-assessment bias about their productivity. We ask whether players benefit from information about the opponents by updating their productivity beliefs which in consequence should reduce competition failure. With a laboratory experiment, we can exogenously vary information that we provide to subjects before they decide about entering the competition or taking an outside option. Subjects enter the competition significantly less often in our information treatments compared to the benchmark treatment. The two main contributions of this study are firstly, simple aggregated information on the productivity distribution significantly reduces competition failure by up to $57 \%$, and secondly, aggregated information is sufficient and more detailed information does not further reduce inefficiency. The information provision does not directly disperse the self-assessment bias, but it raises the awareness for the opponent's potentially high productivity and mitigates the consequences. Our findings suggest a simple and inexpensive way to reduce decision making that yields less monetary utility by increasing individuals' appreciation of the decision problem.

An interesting extension in the field would be an implementation at an employment agency or job center. The agency could provide aggregated information for startup businesses like Ich-AGs in Germany (You-Inc.) 11 For example, an entrepreneur who wants to start a restaurant could receive information on the current amount of restaurants and restaurant failures. We expect less business openings and less frequent business failures. In a similar vein, firms could provide a distribution of the qualification of their workers before the hiring process to reduce the amount of applications and organizational costs. Inexpensive information which is simple to understand might also be valuable in other economic contexts. Providing information about competitors could reduce the baneful effects of overconfidence in economic environments like labor negotiations, litigation, or stock trading.

\footnotetext{
${ }^{11}$ Caliendo, Kritikos, Steiner, and Wießner (2007) show that 20-40\% of You-Inc. start ups ("Ich-AG") do not exists anymore after 16 month and particular groups like facility managers fail especially often, because the demand is already exhausted.
} 


\section{References}

Baldwin, J. R. (1995): The Dynamics of Industrial Competition. Cambridge University Press.

Bartling, B., E. Fehr, M. Marechal, and D. Schunk (2009): "Egalitarianism and Competitiveness," American Economic Review, 99(2), 93-98.

Bénabou, R., and J. Tirole (2002): "Self-Confidence and Personal Motivation," Quarterly Journal of Economics, 117(3), 871-915.

Brunnermeier, M. K., and J. A. Parker (2005): "Optimal Expectations," American Economic Review, 95(4), 1092-1118.

Burks, S. V., J. P. Carpenter, L. Goette, and A. Rustichini (2010): "Overconfidence is a Social Signaling Bias," Working Paper.

Caliendo, M., A. Kritikos, V. Steiner, and F. Wiessner (2007): "Existenzgründungen Unterm Strich ein Erfolg," IAB Kurzbericht, 10.

Camerer, C., and D. Lovallo (1999): "Overconfidence and Excess Entry: An Experimental Approach," American Economic Review, 89(1), 306-318.

Charness, G., A. Rustichini, and J. van de Ven (2011): "Self-confidence and Strategic Deterrence," Working Paper.

Choi, J., D. Laibson, B. Madrian, and A. Metrick (2003): "Optimal Defaults," American Economic Review, 93, 180-185.

Cooper, A. C., C. Y. Woo, and W. C. Dunkelberg (1988): "Entrepreneurs' Perceived Chances for Success," Journal of Business Venturing, 3(2), 97-108.

Daniel, K. D., D. Hirshleifer, and A. Subrahmanyam (2001): "Overconfidence, Arbitrage, and Equilibrium Asset Pricing," Journal of Finance, 56(3), 921-965.

Dohmen, T., And A. Falk (2011): "Performance Pay and Multi-dimensional Sorting: Productivity, Preferences and Gender," American Economic Review, 101 (2), 556-590. 
Dunning, J., J. Meyerowitz, and A. Holzberg (1989): "Ambiguity and Self-Evaluation: The Role of Idiosyncratic Trait Definitions in Self-serving Assessments of Ability," Journal of Personality and Social Psychology, 57(6), 1082-1090.

Ewers, M., and F. Zimmermann (2011): "Image and Misreporting," Working Paper, pp. 1-25.

FischBacher, U. (2007): "z-Tree: Zurich Toolbox for Ready-made Economic Experiments," Experimental Economics, 10(2), 171-178.

Gneezy, U., M. Niederle, and A. Rustichini (2003): "Performance in Competitive Environments: Gender Differences August," Quarterly Journal of Economics, pp. 1049-1074.

GreineR, B. (2004): "The Online Recruitment System ORSEE 2.0 - A Guide for the Organization of Experiments in Economics," Working Paper Series in Economics, 10.

Healy, P., and D. Moore (2008a): "Bayesian Overconfidence," Working Paper.

— (2008b): "The Trouble with Overconfidence," Psychological Review, 115(2), 502-517.

Kôszegi, B. (2006): "Ego Utility, Overconfidence, and Task Choice," Journal of the European Economic Association, 4(4), 673-707.

Koellinger, P., M. Minniti, And C. Schade (2007): “I think I can, I think I can': Overconfidence and Entrepreneurial Behavior," Journal of Economic Psychology, 28, 507-527.

MalmendieR, U., and G. Tate (2008): "Who Makes Acquisitions? CEO Overconfidence and the Market's Reaction," Journal of Financial Economics, 89 (1), 20-43.

Möbius, M. M., M. Niederle, P. Niehaus, and T. S. Rosenblat (2011): "Managing SelfConfidence: Theory and Experimental Evidence," working Paper.

Neale, M. A., and M. H. Bazerman (1985): "The Effects of Framing and Negotiator Overconfidence on Bargaining Behaviors and Outcomes.," Academy of Management Journal, 28.

Niederle, M., And L. Vesterlund (2007): "Do Women Shy Away from Competition? Do Men Compete too Much?," Quarterly Journal of Economics, 122(3), 1067-1101. 
Odean, T. (1998): "Volume, Volatility, Price, and Profit when All Traders are Above Average," Journal of Finance, 53(6), 1887-1934.

Reuben, E., P. Rey-Biel, P. Sapienza, and L. Zingales (2010): "The Emergence of Male Leadership in Competitive Environments," IZA Discussion Paper, 5300.

Taylor, S. E., And J. D. Brown (1988): "Illusion and Well-being: A Social Psychological Perspective on Mental Health," Psychological Bulletin, 103, 193-210.

Thaler, R., and C. Sunstein (2003): "Libertarian Paternalism," American Economic Review, 93, 175-179.

(2008): Nudge: Improving Decisions About Health, Wealth, and Happiness. Yale University Press.

Weinstein, N. D. (1980): "Unrealistic Optimism about Future Life Events," Journal of Personality and Social Psychology, 39, 806-820. 


\section{Appendix A}

Figure 3: Histograms of overconfidence measures (i) to (v)
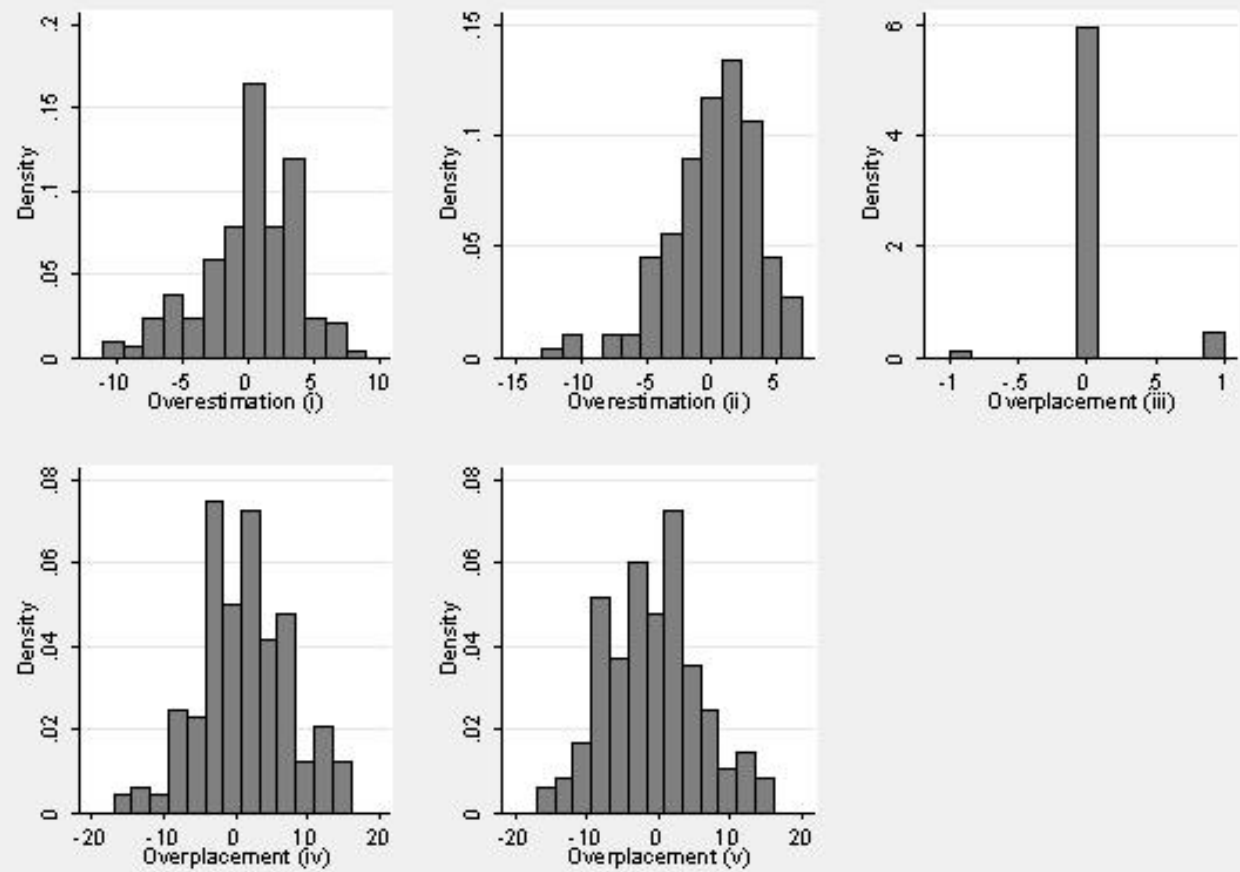
Table 4: Correlation table of our five measures of overconfidence and quiz productivity

\begin{tabular}{|c|c|c|c|c|c|}
\hline & \multicolumn{2}{|c|}{ Overestimation } & \multicolumn{3}{|c|}{ Overplacement } \\
\hline & (i) & (ii) & (iii) & (iv) & $(\mathrm{v})$ \\
\hline (i) & 1 & & & & \\
\hline (ii) & $0.77^{* * *}$ & 1 & & & \\
\hline (iii) & $0.26^{* * *}$ & $0.22^{* * *}$ & 1 & & \\
\hline (iv) & $0.41^{* * *}$ & $0.44^{* * *}$ & $0.46^{* * *}$ & 1 & \\
\hline$(\mathrm{v})$ & $0.36^{* * *}$ & $0.38^{* * *}$ & $0.44^{* * *}$ & $0.90^{* * *}$ & 1 \\
\hline Quiz productivity & $-0.14^{*}$ & $-0.19 * * *$ & $-0.25^{* * *}$ & $-0.68 * * *$ & $-0.68^{* * *}$ \\
\hline
\end{tabular}

Notes: $\mathrm{N}=190$. Significance of the Spearman-rank test at the 1, 5, and 10 percent level is denoted by ***, ${ }^{* *}$, and ${ }^{*}$, respectively.

Table 5: Measures of absolute and relative overconfidence

\begin{tabular}{ll}
\hline \hline Measure & Level of overconfidence \\
\hline (i) Degenerate & $=$ answer $-a_{i}=\triangle_{i}$ \\
(ii) Token distribution task & $=\sum_{i=0}^{20} t_{i} \cdot i / 20-a_{i}$, where $t_{i}$ is the amount of token for category $i$ \\
(iii) Median & $= \begin{cases}1 & \text { if worse than median although indicated better than median } \\
0 & \text { if median comparison is correct } \\
-1 & \text { if better than median although indicated worse than median }\end{cases}$ \\
(iv) Upward distribution & $=n_{\text {better }}-$ answer \\
(iv) Downward distribution & $=$ answer $-n_{\text {worse }}$
\end{tabular}

